\title{
Pendugaan Lapisan Akuifer Menggunakan Metode Geolistrik dengan Teknik Vertical Electrical Sounding (VES) \\ di Lokasi TPA Sampah Desa Jononunu, Parigi, Sulawesi Tengah

\author{
Estimation of Aquifer Layer Using The Geoelectrical Method \\ with Vertical Electrical Sounding (VES) Technique \\ at The Location of TPA Jononunu, Parigi, Central Celebes
}

\author{
Asrafil $^{1^{*}}$, Muslimin U Botjing ${ }^{1}$ dan Sitti Rugayya ${ }^{2}$ \\ ${ }^{1}$ Program Studi Teknik Geologi, Fakultas Teknik, Universitas Tadulako \\ ${ }^{2}$ Jurusan Fisika, Fakultas MIPA, Universitas Tadulako
}

\begin{abstract}
The research area is the construction site of waste management (TPA), which will produce liquid waste that can pollute the subsurface water. This study aims to identify subsurface aquifer (aquifer layer) of research sites by applying the geoelectrical method of The Vertical Electrical Sounding (VES) technique. The method was applied to estimate the material layers in the subsurface based resistivity properties were obtained. Field investigations in the research area is carried out by Schlumberger electrode configuration with inversion processing data using software PROGRESS. The interpretation of the correlation between grades and lithology resitivity research areas are four layers consisting of a layer of topsoil in the form of sandy and loose soil; aquiclud layer consists of clay, silty sand, silt-fine sand; aquifer layer consisting of medium-coarse sand; and a layer of weathered bedrock. Aquifer layer obtained has a thickness of 3.44 to 8.57 meters with resistivity values in the range $291.01-402.01 \Omega \mathrm{m}$, at a depth varying in the range of $10.97-19.52$ meters from the ground.
\end{abstract}

Keywords: Aquifer, Geoelectrical, Vertical Electrical Sounding, Resistivity.

\begin{abstract}
ABSTRAK
Daerah penelitian merupakan lokasi dibangunnya sarana pengelolaan sampah (TPA), yang nantinya akan menghasilkan limbah cair yang dapat mencemari air bawah permukaan. Penelitian ini bertujuan untuk mengidentifikasi lapisan air tanah bawah permukaan (lapisan akuifer) pada lokasi penelitian dengan menerapkan metode geolistrik teknik Vertical Electrical Sounding (VES). Metode ini diterapkan untuk menduga lapisan material di bawah permukaan bumi berdasarkan sifat resistivitas yang diperoleh. Penyelidikan lapangan di daerah penelitian dilakukan dengan konfigurasi elektroda Schlumberger dengan pengolahan data secara inversi menggunakan perangkat lunak PROGRESS. Hasil interpretasi korelasi antara nilai resitivitas dan litologi daerah penelitian diperoleh empat lapisan yang terdiri dari lapisan topsoil yang berupa tanah berpasir dan gembur; lapisan akuiklud terdiri dari lempung,
\end{abstract}


pasirlempungan, lumpur-pasirhalus; lapisan akuifer yang terdiri dari pasir sedang-kasar; dan Lapisan bedrock lapuk. Lapisan akuifer diperoleh memiliki ketebalan 3,44 - 8,57 meter dengan nilai resistivitas dalam rentang 291,01-402,01 $\Omega \mathrm{m}$, pada kedalaman bervariasi dalam rentang 10.97 - 19.52 meter dari permukaan tanah.

\section{Kata Kunci : Akuifer, geolistrik, Vertical Electrical Sounding, Resistivitas}

\section{LATAR BELAKANG}

Di wilayah Desa Jononunu dibangun sarana pengelolaan sampah yang dikenal dengan Tempat Pembuangan Akhir (TPA) sampah. Untuk itu diperlukan perencanaan pengelolaan air limbah di lokasi TPA sampah tersebut. Salah satu aspek pertimbangan dan kajian yang dilakukan dalam perencanaan pengelolaan air limbah TPA sampah adalah diketahuinya lapisan air tanah bawah permukaan (lapisan akuifer). Untuk dapat mengetahui parameter tersebut, salah satu metode yang dapat digunakan adalah menggunakan metode geolistrik dengan teknik Vertical Electrical Sounding (VES). Metode ini cukup afisien dan efektif dalam mengidentifikasi lapisan akuifer bawah permukaan.

Secara geografis, lokasi penelitian berada pada koordinat $120^{\circ}$ 6' $25.2^{\prime \prime}$ LS 1206’32.4” LS dan 046'40.8” BT 046’37.2” BT. Lokasi penelitian berjarak $\pm 75 \mathrm{~km}$ dari Kota Palu dan berada di perbukitan rendah dengan ketinggian berkisar 50 -75 mdpl (Gambar 1).

Secara geologi regional, daerah studi tersusun oleh Formasi Molasa Celebes yang terdiri atas konglomerat, batupasir, batulumpur, batu gamping koral, dan napal (Sukamto, 1973). Pada permukaan terdapat tanah dengan tekstur pasir dengan ketebalan bervariasi.

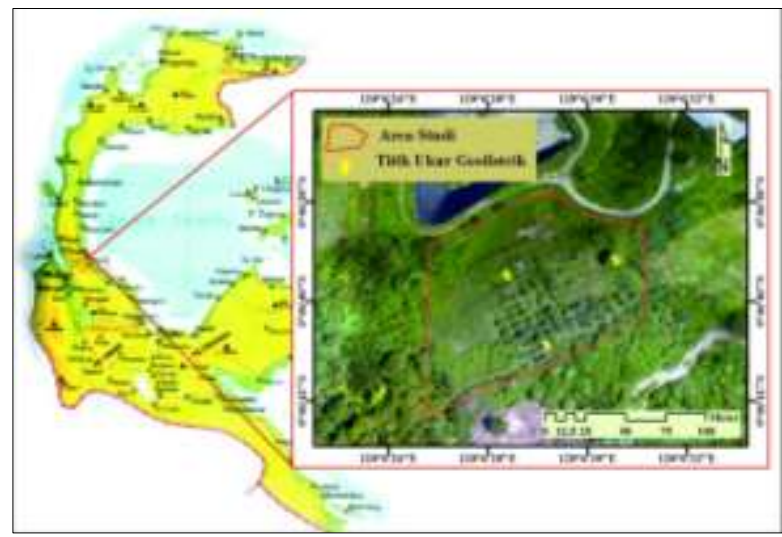

Gambar 1. Lokasi Daerah Penelitian

Daerah Studi ini termasuk dalam zona akuifer dengan aliran melalui ruang antar butir. Akuifer ini umumnya merupakan hasil rombakan batuan, berukuran halus sampai kasar, terdiri dari pasir lempungan pasir, kerikil dan kerakal. Kedudukan muka air tanah bebas kurang dari $3 \mathrm{~m}$ dibawah muka tanah setempat, debit sumur gali diperkirakan dapat mencapai 5 ltr/det (Kepmen PU, 2012).

Penelitian ini bertujuan untuk mengidentifikasi lapisan air tanah bawah permukaan (lapisan akuifer) pada lokasi penelitian. Dari hasil penelitian ini diharapkan dapat menjadi data base dan 
bahan pertimbangan dalam perencanaan pengelolaan air limbah TPA sampah di

Desa Jononunu.

\section{BAHAN DAN METODE}

\section{Alat dan Bahan}

Peralatan yang digunakan dalam studi penyelidikan air tanah ini, yakni ;

1. Handhelds GPS merek Garmin

2. Kompas

3. Meteran Ukur/Rollmeter

4. Satu Set Alat Ukur Geolistrik, yakni terdiri dari ;

a. Satu unit instrumen resistivitimeter.

b. Power Supply (DC)/Accu

c. Dua pasang elektroda arus dan potensial

d. Empat roll kabel penghubung.

e. Meteran Ukur/Rollmeter

5. Konduktivitymeter untuk mengukur daya hantar listrik (DHL) air.

6. Palu Geologi

\section{Metode VES}

Metode VES atau Vertical Electrical Sounding adalah salah satu dari metode geolistrik (Lowrie, 2007). Metode VES digunakan untuk menduga lapisan-lapisan material di bawah permukaan Bumi berdasarkan sifat resistivitasnya (Telford et al., 2004). Nilai resistivitas ( $\rho$ ) dihitung berdasarkan data arus listrik (I) dan beda potensial (V) yang diperoleh di lapangan. Data arus listrik dan beda potensial diperoleh dari injeksi arus listrik ke bawah permukaan bumi melalui pasangan elektroda arus $(\mathrm{C} 1, \mathrm{C} 2)$ dan elektroda potensial (P1, P2) (Loke, 2000).

Penyelidikan lapangan di daerah studi menggunakan metoda pengukuran geolistrik Teknik VES dengan konfigurasi elektroda Schlumberger (Gambar 2). Faktor geometri untuk konfigurasi ini diberikan oleh persamaan :

$$
K=\frac{\pi\left(L^{2}-l^{2}\right)}{2 l}
$$

Sedangkan nilai hambatan jenis semu diperoleh melalui persamaan :

$$
\rho=K \frac{\Delta V}{I}
$$

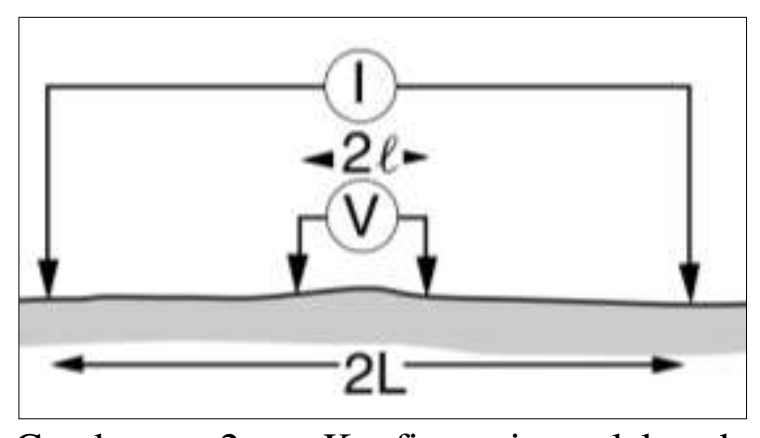

Gambar 2. Konfigurasi elektroda Schlumberger (Milsom, 2003)

Metoda pengukuran ini cukup baik untuk menentukan zona basah (akuifer) bawah permukaan secara akurat dan murah. Lapisan akuifer dicirikan dengan adanya pori-pori dan permeabilitas (hubungan antar pori) yang besar pada batuan, sehingga air tertampung dan dapat mengalir di dalamnya. Adanya kandungan air pada lapisan akuifer menjadikan lapisan ini 
sebagai zona basah dan konduktif sehingga membedakan dengan lapisan lainnya. Lapisan tanah (konduktif) seperti ini biasanya memiliki harga hambatan jenis/resistivitas tertentu. Dengan mengetahui nilai hambatan jenis lapisan bumi bawah permukaan, maka dapat diprediksikan lapisan-lapisan tanah atau batuan yang tersaturasi air. Hal ini cukup bermanfaat untuk memprediksi lokasi dan kedalaman dalam mengekploitasi airtanah.

Jenis batuan yang dapat bertindak sebagai lapisan pembawa air (akuifer) mempunyai harga hambatan jenis yang sangat bervariasi yang ditentukan oleh beberapa faktor, seperti: jenis material, ukuran, densitas, porositas dan bentuk poripori batuan, kandungan air, kualitas air, dan suhu. Hubungan antara hambatan jenis batuan $\rho$ dengan porositas $\phi$ (dinyatakan sebagai fraksi per satuan volume batuan) yang terisi penuh oleh air pori pertama kali diusulkan oleh Archie pada Tahun 1942 melalui Persamaan Archie I:

$$
\rho=a \rho_{w} \phi^{-m}
$$

dengan $\rho$ adalah hambatan jenis batuan yang terukur, $\rho_{w}$ hambatan jenis air pengisi pori yang diukur dari air formasi atau dihitung. a konstanta yang mencirikan jenis karakter batuan (tekstur, bentuk, dan lain-lain), sedangkan $\mathrm{m}$ adalah konstanta yang mencirikan karakter sementasi.
Hubungan hambatan jenis dalam persamaan (3) direfleksikan dengan besar faktor formasi (F), yaitu :

$$
F=\frac{\rho}{\rho_{w}}=\frac{a}{\phi^{-m}}
$$

Faktor formasi dapat digunakan untuk pendugaan zona akuifer sebab besaran tersebut berefleksi sebagai porositas pada batuan sedimen maupun batuan beku yang mengalami rekahan. hambatan jenis air pengisi pori $\rho w$, selain dapat diukur langsung, juga dapat dihitung dengan menggunakan persamaan :

$$
\rho_{w}=10000 / D H L
$$

Dimana DHL $(\mu S)$ adalah konduktivitas atau daya hantar listrik airtanah.

Beberapa kesimpulan nilai faktor formasi dari bebarapa studi hidrologi yang diperoleh Boehmer (Taib, 2000), seperti dalam Tabel 1 dan Tabel 2 berikut.

Tabel 1. Klasifikasi pendugaan faktor formasi untuk batuan sedimen

\begin{tabular}{|c|c|c|}
\hline $\mathrm{F}$ & Formasi & Aquiver/Aquiclude \\
\hline$\leq 1$ & Clay & Aquiclude \\
\hline $1-$ & Peat, clayey & Aquiclude \\
\hline 2 & Silt - find sand & Poor to medium \\
\hline 3 & Medium sand & Medium to \\
\hline 4 & Coarse sand & Produktive aquiver \\
\hline 5 & Gravel & Higly produktive \\
\hline
\end{tabular}


Tabel 2. Klasifikasi pendugaan faktor formasi untuk batuan vulkanik dan beku

\begin{tabular}{|c|c|c|c|}
\hline Formasi & $\begin{array}{c}\text { Permeable/ } \\
\text { impermeable }\end{array}$ & $\mathrm{F}$ & Permeable/ impermeable \\
\hline Tuffa gunung api & Impermeable & $1<\mathrm{F}<4$ & Permeable \\
\hline Basalt rekahan & Permeable & $5<\mathrm{F}<15$ & Solid \\
\hline Breksi & Permeable & $\begin{array}{c}3<\mathrm{F}<7 \\
>10\end{array}$ & $\begin{array}{c}\text { Permeable } \\
\text { Impermeable (Solid) }\end{array}$ \\
\hline Batugamping & Permeable & $3<\mathrm{F}<10$ & Solid \\
\hline
\end{tabular}

Tabel. 3 Tabulasi Hasil Pengolahan Data Geolistrik VES dengan PROGRESS.

\begin{tabular}{|c|c|c|c|c|c|c|c|c|c|}
\hline \hline \multirow{2}{*}{$\begin{array}{c}\text { TITIK } \\
\text { UKUR }\end{array}$} & \multicolumn{7}{|c|}{ LAPISAN } & \multirow{2}{*}{ KET. } \\
\cline { 2 - 9 } & 1 & 2 & 3 & 4 & 5 & 6 & 7 & \\
\hline \hline \multirow{2}{*}{$\mathrm{G} 01$} & $\rho(\Omega \mathrm{m})$ & 1121.44 & 47.38 & 402.01 & 101.29 & 421.04 & 95.08 & & \\
\cline { 2 - 10 } & $d(\mathrm{~m})$ & 1.24 & 10.97 & 19.54 & 29.41 & 39.85 & & & \\
\hline \multirow{2}{*}{$\mathrm{G} 02$} & $\rho(\Omega \mathrm{m})$ & 766.68 & 92.75 & 140.88 & 291.01 & 7199.46 & & & \\
\cline { 2 - 9 } & $d(\mathrm{~m})$ & 1.21 & 16.88 & 19.52 & 23.03 & & & & \\
\hline \multirow{2}{*}{$\mathrm{G} 03$} & $\rho(\Omega \mathrm{m})$ & 1052.27 & 169.78 & 8.81 & 144.42 & 323.70 & 3861.12 & & \\
\cline { 2 - 9 } & $d(\mathrm{~m})$ & 0.90 & 8.41 & 10.94 & 14.81 & 18.25 & & & \\
\hline
\end{tabular}

\section{Akusisi Data}

Akuisi data dilakukan di tiga titik yang tersebar di lokasi studi. Di tiap titik ukur dilakukan pembacaan koordinat geografis melalui alat GPS. Injeksi arus listrik dilakukan melalui susunan elektroda dalam konfigurasi Schlumberger. Arus listrik mengalir dalam rangkaian yang tampak pada Gambar 2. Pasangan elektroda arus $(\mathrm{C} 1, \mathrm{C} 2)$ disusun dengan jarak yang lebih besar dibandingkan pasangan elektroda potensial (P1, P2). Jarak antar pasangan elektroda arus ( $\mathrm{AB}$ atau $\mathrm{L}$ ) diperbesar untuk mengukur nilai resistivitas material yang lebih dalam. Saat beda potensial mulai sulit terukur, sensitivitas alat berkurang sehingga jarak antar pasangan elektroda potensial ( $\mathrm{MN}$ atau a) harus diperbesar. Besarnya arus listrik dan beda potensial untuk masing-masing jarak elektroda arus dan elektoda potensial dicatat untuk menghitung nilai resistivitas semu dari material penyusun di bawah permukaan.

\section{Pengolahan dan Interpretasi Data}

Hasil akuisi data berupa data arus listrik dan beda potensial. Proses pengolahan data membutuhkan data resistivitas semu bukan data arus listrik (I) dan beda potensial (V). Nilai resistivitas semu $(\rho a)$ dihitung berdasarkan data arus 
listrik dan beda potensial dengan menggunakan formulasi sebagai berikut:

$$
\rho a=R \cdot k
$$

Untuk memperoleh nilai $\rho$ (resistivitas sebenarnya) dilakukan dengan teknik pemodelan inversi. Pemprosesan inversi ini dilakukan dengan menggunakan perangkat lunak PROGRESS. Teknik pemodelan inversi ini mengubah nilai resistivitas semu menjadi nilai resistivitas material sebenarnya.

Interpretasi data dilakukan dengan membandingkan nilai resistivitas hasil proses inversi dengan nilai resistivitas material umum penyusun bumi.

\section{HASIL DAN PEMBAHASAN}

\section{Hasil}

Berdasarkan data hasil pengukuran metode geolistrik dari titik G01 hingga G03 yang diperoleh di lapangan, dilakukan pengolahan dengan inversi menggunakan perangkat lunak PROGRESS. Hasil pengolahan data memberikan nilai resistivitas $(\rho)$ dan kedalaman lapisan per resistivitas yang bervariasi. Hasil pengolahan data untuk setiap titik ukur geolistrik disajikan dalam bentuk Tabel 3 berikut.

\section{Pembahasan}

Berdasarkan hasil pengolahan data terhadap 3 titik pengukuran geolistrik dengan mempertimbangakan keadaan geologi dan nilai faktor formasi, maka diperoleh korelasi antara nilai resitivitas dengan litologi daerah studi. Secara umum, nilai resistivitas yang diperoleh diinterpretasi sebagai berikut.

a. Lapisan topsoil (tanah penutup) dengan nilai resistivitas yang sangat besar, dikarenakan tekstur tanah penutup yang berpasir dan gembur. Lapisan ini berkedudukan paling atas, diduga tebal lapisan berkisar 0,9-1,24 meter.

b. Lapisan akuiklud yang terdiri dari lempung, pasirlempungan, lumpurpasirhalus dengan nilai resistivitas dalam rentang 8,81 - 29,41 $\Omega$ m. Diduga ketebalan lapisan ini berkisar 9,73 20,31 meter.

c. Lapisan Akuifer yang terdiri dari pasir sedang-kasar dengan nilai resistivitas dalam rentang 291,01- 02,01 $\Omega \mathrm{m}$. Diduga ketebalan lapisan berkisar antara 3,44 - 8,57 meter. Kedalaman kontak lapisan ini dengan lapisan di atasnya, diasumsikan sebagai kedalaman muka air tanah.

d. Lapisan bedrock lapuk dengan kisaran nilai resistivitas mencapai ribuan ohmmeter yang diduga sebagai batuan yang berasal dari Komplek Batuan Metamorf, terukur di titik G02 dan G03 pada kedalaman 18,25-23,03 meter dari permukaan tanah. 
Guna memperoleh gambaran tentang susunan lapisan bawah permukaan dari keseluruhan titik ukur geolistrik, dilakukan korelasi antar titik dalam bentuk profil penampang lapisan. Korelasi mengacu pada nilai resistivitas dan pendugaan lapisan di atas, dengan asumsi nilai resistivitas air ( $\rho$ w) tetap terhadap kedalaman. Nilai resistivitas air yang diperoleh dari hasil perhitungan adalah senilai $99.305 \Omega \mathrm{m}$, berdasarkan DHL sampel air yang diperoleh pada sungai yang berada di bagian Selatan area studi yang bernilai $100,7 \mu \mathrm{S}$.

\section{Profil Penampang Lapisan G01-G02}

Profil penampang ini sepanjang \pm 50 meter, dengan arah titik G01 ke G02 relatif Baratlaut $\left(\mathrm{N} 330^{\circ} \mathrm{E}\right)$. Susunan lapisan di antara titik ukur geolistrik G01 ke titik G02 diinterpretasikan dalam bentuk profil penampang berikut (Gambar 3). Berdasarkan korelasi antar titik ukur geolistrik hasil interpretasi dalam bentuk profil penampang, diperoleh gambaran kedudukan lapisan akuifer dengan lapisan lainnya. kedudukan lapisan akuifer yang dibatasi oleh lapisan akuiklud menunjukkan lapisan akuifer ini tergolong confined Aquiver (akuifer tertekan).

Korelasi antar lapisan G01-G02 dan G01-G03 menunjukkan arah aliran air tanah bergerak dari titik G01 menuju titik lainnya (G02 dan G03). Kedudukan elevasi
G02 lebih tinggi dari G03, namun kedudukan kedalaman lapisan akuifer G03 lebih dangkal (rendah) dari titik G02.

\section{Profil Penampang Lapisan G01-G03}

Profil penampang ke dua memiliki panjang 68 meter (merupakan jarak antara titik ukur geolistrik G01 ke G03). Korelasi yang dibentukan antar titik ukur geolistrik ini berarah relatif Timurlaut $\left(\mathrm{N} 38^{\circ} \mathrm{E}\right)$. Berikut gambar (Gambar 4) profil penampang lapisan G01-G03, hasil interpretasi korelasi antar lapisannya.

\section{Profil Penampang Lapisan G02-G03}

Profil penampang korelasi antar lapisan dari titik ukur geolistrik G02 ke titik ukur geolistrik G03 diilustrasikan pada Gambar 5. Panjang penampang (jarak antar titik ukur) bernilai 69 meter dan arah relatif ke Timur $\left(\mathrm{N} 81^{\circ} \mathrm{E}\right)$ dari G02 ke G03.

Dengan mempertimbangkan bahwa umumnya airtanah mengalir dari daerah yang lebih tinggi menuju daerah yang lebih rendah dan posisi lokasi area studi dimana daerah sebelah Barat area studi merupakan daerah tangkapan air (recharge area), kemudian sebelah Timur merupakan daerah lepasan air (dischage area), maka diinterpretasikan bahwa arah aliran air tanah tidak bergerak dari titik ukur G03 ke titik ukur G02, melainkan tegak lurus dari lintasan profil penampang lapisan G02G03. Sehingga Berdasarkan kedudukan dan kedalaman akuifer dari masing-masing 
interpetasi penampang lapisan diperoleh gambaran bahwa arah aliran tanah di area studi menuju ke arah relatif TimurlautTimur, menuju daerah yang lebih rendah.

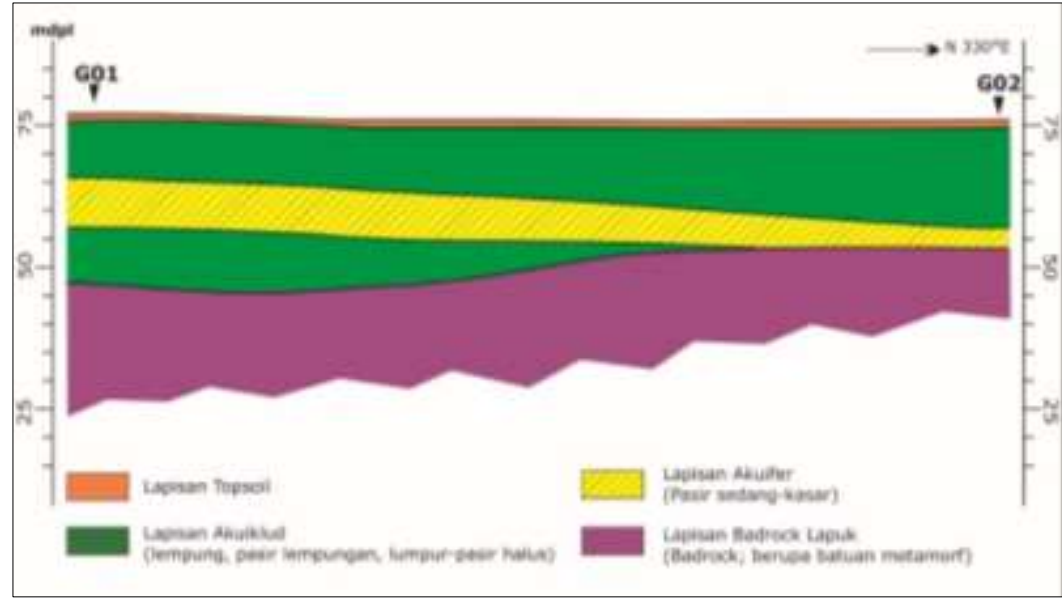

Gambar 3. Gambar profil penampang titik ukur geolistrik G01-G02

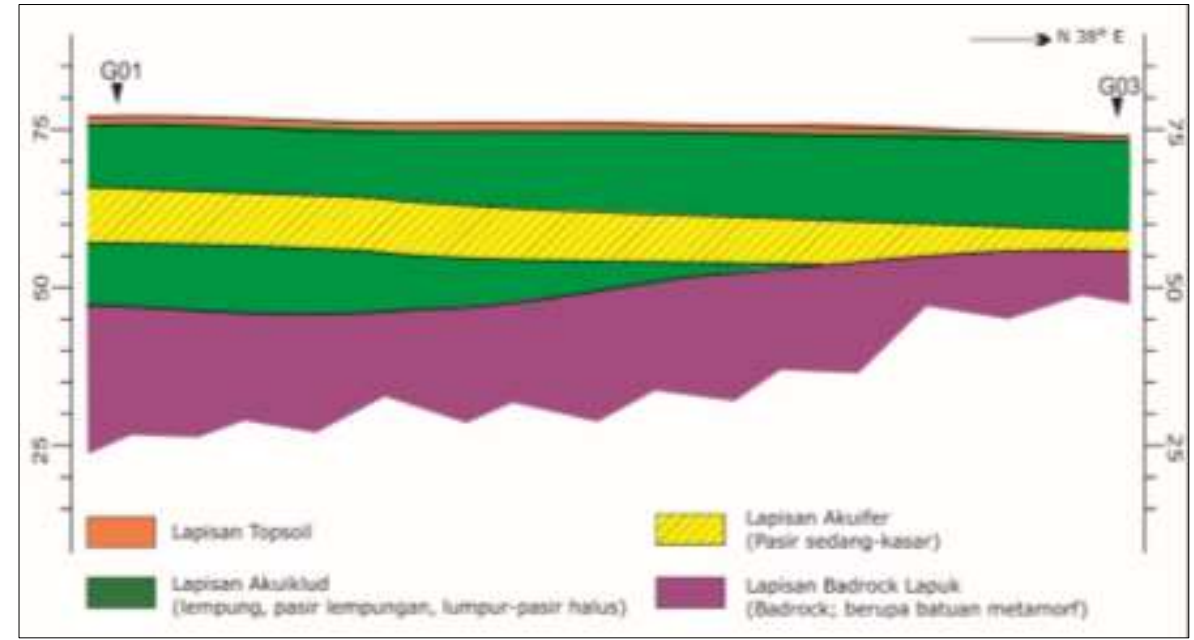

Gambar 4. Gambar profil penampang titik ukur geolistrik G01-G03

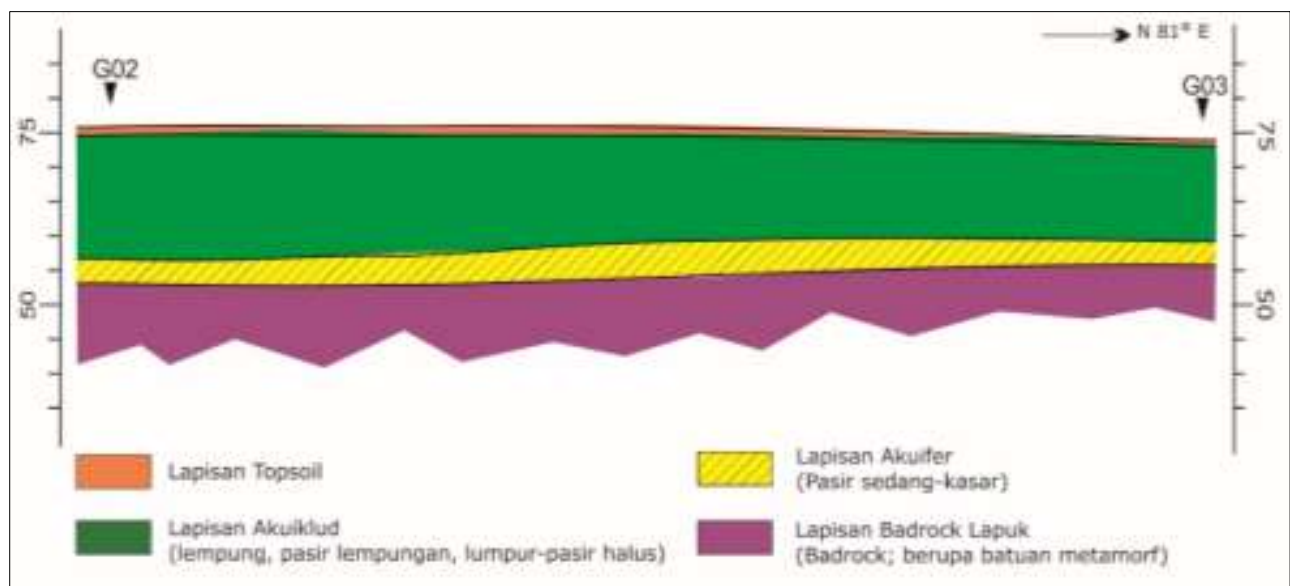

Gambar 5. Gambar profil penampang titik ukur geolistrik G02-G03 


\section{UCAPAN TERIMAKASIH}

Ucapan terima kasih bagi PT Hexa

Mulia Konsultan yang memfasilitasi dilakukannya penelitian ini dengan menganggarkan biaya survey geolistrik guna melengkapi data dan sebagai bahan pertimbangan dalam penyusunan outline plan dan DED sistem pengelolaan air limbah kab. Parigi Moutong tahun 2016.

\section{DAFTAR PUSTAKA}

Kepmen PU, 2012, Pola Pengelolaan Sumberdaya Air Wilayah Sungai Parigi-Poso. Kementerian Pekerjaan Umum, Jakarta.

Lowrie, W., 2007, Fundamentals of Geophysics, 2nd Edition, Cambridge: Cambridge University Press.

Loke, M.H., 2000, Electrical Imaging Survey for Environmental and Engineering Studies, Diterima 06 Maret 2009, dari http://www.geometrics.com.

Milsom, J., 2003, Field Geophysics, Third Edition, John Wiley and Sonds Ltd; London.

Sukamto, R., 1973, Peta Geologi Tinjau Lembar Palu Sulawesi, Skala 1 : 250.000, Pusat Penelitian dan Pengembangan Geologi, Bandung.

Taib, M.I.T., 2000, Dasar Metoda Eksplorasi Tahanan Jenis Galvanik, Diktat kuliah, Jurusan Teknik Geofisika FIKTM ITB Bandung

Telford, W.M., L.P Geldart, dan R.E. Sheriff, 2004, Applied Geophysics, 2nd Edition, Cambridge: Cambridge University Press 